Communication

\title{
A Novel Peptide as a Specific and Selective Probe for Klebsiella pneumoniae Detection
}

\author{
Hyun Kim ${ }^{1,+}{ }^{+}$Ju Hye Jang ${ }^{1, \dagger}$, In Young Jung ${ }^{2}$ and Ju Hyun Cho ${ }^{1,2,3, *}$ \\ 1 Research Institute of Life Sciences, Gyeongsang National University, Jinju 52828, Korea; \\ hyun.kim@gnu.ac.kr (H.K.); juhye.jang@gnu.ac.kr (J.H.J.) \\ 2 Division of Applied Life Science (BK21Four), Gyeongsang National University, Jinju 52828, Korea; \\ inyoung.jung@gnu.ac.kr \\ 3 Division of Life Science, Gyeongsang National University, Jinju 52828, Korea \\ * Correspondence: juhyun.cho@gnu.ac.kr; Tel.: +82-55-772-1347; Fax: +82-55-772-1349 \\ + These authors contributed equally to this work.
}

Citation: Kim, H.; Jang, J.H.; Jung, I.Y.; Cho, J.H. A Novel Peptide as a Specific and Selective Probe for Klebsiella pneumoniae Detection. Biosensors 2022, 12, 153. https:// doi.org/10.3390/bios12030153

Received: 25 January 2022 Accepted: 28 February 2022 Published: 1 March 2022

Publisher's Note: MDPI stays neutral with regard to jurisdictional claims in published maps and institutional affiliations.

Copyright: (C) 2022 by the authors. Licensee MDPI, Basel, Switzerland. This article is an open access article distributed under the terms and conditions of the Creative Commons Attribution (CC BY) license (https:// creativecommons.org/licenses/by/ $4.0 /)$.

\begin{abstract}
Klebsiella pneumoniae is infamous for generating hospital-acquired infections, many of which are difficult to treat due to the bacterium's multidrug resistance. A sensitive and robust detection method of K. pneumoniae can help prevent a disease outbreak. Herein, we used K. pneumoniae cells as bait to screen a commercially available phage-displayed random peptide library for peptides that could be used to detect K. pneumoniae. The biopanning-derived peptide TSATKFMMNLSP, named KP peptide, displayed a high selectivity for the K. pneumoniae with low cross-reactivity to related Gram-negative bacteria. The specific interaction between KP peptide and K. pneumoniae lipopolysaccharide resulted in the peptide's selectivity against K. pneumoniae. Quantitative analysis of this interaction by enzyme-linked immunosorbent assay revealed that the KP peptide possessed higher specificity and sensitivity toward K. pneumoniae than commercially available anti-Klebsiella spp. antibodies and could detect $K$. pneumoniae at a detection limit of $10^{4} \mathrm{CFU} / \mathrm{mL}$. These results suggest that KP peptide can be a promising alternative to antibodies in developing a biosensor system for $K$. pneumoniae detection.
\end{abstract}

Keywords: Klebsiella pneumoniae; phage display peptide; pathogen detection; lipopolysaccharide; selective probe

\section{Introduction}

Hospital-acquired infections (HAIs) are considered a public health concern because they increase mortality and morbidity, lengthen hospitalization, and result in high healthcare costs [1]. A leading cause of these HAIs is Klebsiella pneumoniae, a member of the Enterobacteriaceae family that often causes pneumonia, bacteremia, pyogenic liver abscesses, and urinary tract infections, with the majority of these infections occurring in immunocompromised patients [2]. K. pneumoniae colonizes human mucosal surfaces easily, including the gastrointestinal tract and oropharynx, where its effects appear to be benign [2-4]. K. pneumoniae can enter other tissues from these sites and cause severe infections. Epidemiological data indicate that many hospitalized patients have K. pneumoniae in their gastrointestinal tract, linking K. pneumoniae carriage and subsequent disease from the same isolate [5-7]. Individuals can be silently colonized for extended periods, and these asymptomatic carriers serve as reservoirs for persistent transmission, making spread challenging to control and outbreaks challenging to stop [8-10]. Moreover, K. pneumoniae infections acquired in hospitals are challenging to treat since many K. pneumoniae strains have become highly drug-resistant [11,12]. Hence, this bacterium's rapid, precise, and sensitive identification is required to guide the appropriate therapy and control the pathogen's spread.

Microscopic examination, biochemical identification, and automatic bacterial detection apparatus such as the VITEK 2 system are traditionally used to detect K. pneumoniae based 
on the phenotypic system. However, they have low sensitivity and are time-consuming due to requiring several days of incubation [13]. PCR-based assays (e.g., conventional PCR, multiplex PCR, or real-time PCR) provide high sensitivity and specificity and have become the gold standard for detecting K. pneumoniae [14-16]. However, PCR-based assays require expensive equipment, trained personnel, and a consistent power supply, making them unsuitable for on-site testing. Recently, several investigators have developed alternative methods, including MALDI-TOF MS [17,18], luminescent phage [19], gold nanoparticle (GNP) [20], and lateral-flow strip immunoassay (LFSA) [21] for K. pneumoniae detection. However, these methods also have drawbacks such as the need for sophisticated equipment (MALDI-TOF MS), the need for a relatively long incubation time (luminescent phage), and low sensitivity (GNP and LFSA).

Biosensors are a sophisticated alternative to commonly used molecular bacterial detection methods, providing cost-effective, specific, sensitive, and in situ real-time monitoring with minimal sample preparation and detection time [22]. Biosensors are essentially made up of a recognition element coupled to a transducer that converts specific analyte binding to receptors into a detectable or measurable readout $[23,24]$. Therefore, developing biosensors with high sensitivity and specificity requires the design and use of recognition elements that specifically bind to the pathogen of interest. Although antibodies are the most commonly used recognition element in affinity biosensor research, their production and purification costs, as well as their stability during and after immobilization on sensor surfaces, are difficult to manage [24]. Short peptides derived from phage-displayed libraries have recently been introduced as an intriguing alternative for developing novel biosensing platforms. As opposed to antibodies, peptides are more stable and easier to manipulate at the molecular level, and they have a low manufacturing cost $[25,26]$. In fact, phage-displayed peptides have been successfully employed as molecular recognition elements for the detection of bacterial toxins [27] as well as the identification of Staphylococcus aureus [28,29], Pseudomonas aeruginosa [30], Salmonella typhimurium [31,32], and Bacillus anthracis [33].

In this study, we used a phage display approach to isolate peptides that bind selectively to the surface of K. pneumoniae. The ability of the isolated peptide to interact specifically with K. pneumoniae was assessed using enzyme-linked immunosorbent assay (ELISA) and confocal laser scanning microscopy by comparing it to a panel of other bacterial species. The potential target for the isolated peptide on the K. pneumoniae surface was identified. In addition, the specificity and sensitivity of the isolated peptide for detecting K. pneumoniae were further evaluated in comparison with commercially available antiKlebsiella spp. antibodies.

\section{Materials and Methods}

\subsection{Bacterial Strains and Culture}

The bacterial strains used in this study were obtained from the American Type Culture Collection (ATCC) and the Korean Collection for Type Culture (KCTC) and comprised: K. pneumoniae KCTC 2208, Escherichia coli KCTC 2223, P. aeruginosa ATCC 27853, Pseudomonas putida ATCC 17426, S. typhimurium KCTC 2370, Salmonella enteritidis ATCC 13076, S. aureus KCTC 1621, Staphylococcus epidermidis KCTC 1917, Enterococcus faecalis KCTC 2011, Bacillus subtilis ATCC 6633, and Lactococcus lactis ATCC 11454. Clinically isolated K. pneumoniae strains (KBN 12P00150, KBN 12P00173, KBN 12P00237, and KBN 12P02404) and antibiotic-resistant K. pneumoniae strains [NCCP 15782 (NDM-1), NCCP 16124 (GES-5), and NCCP 16128 (OXA-232)] were obtained from the Gyeongsang National University Hospital Culture Collection for Pathogens and National Culture Collections for Pathogens, respectively.

Cultures were maintained and subcultured on nutrient agar plates on a regular basis and stored at $4{ }^{\circ} \mathrm{C}$ until tested. Bacterial stock cultures were stored at $-80{ }^{\circ} \mathrm{C}$ in tryptic soy broth (TSB) or M17 broth supplemented with $0.5 \%$ glucose for L. lactis with $20 \%$ glycerol $(v / v)$. In all experiments, log-phase cultures of bacteria grown in TSB (or M17 broth supplemented with $0.5 \%$ glucose for L. lactis) were centrifuged at $3000 \times g$, washed 
three times, and resuspended in phosphate-buffered saline (PBS, pH 7.4). Bacterial titers were determined using optical density measurement and validated by plating on nutrient agar plates.

\subsection{Biopanning of Phage-Displayed Peptides}

The Ph.D-12 Phage Display Peptide Library (New England Biolabs, Ipswich, MA, USA) was screened for K. pneumoniae-binding phages as previously described with slight modifications [34]. To ensure specificity, the phage library was depleted of clones binding to bovine serum albumin (BSA)-coated wells before selecting K. pneumoniae-binding clones. For the first round of biopanning, K. pneumoniae KCTC 2208 cells resuspended in PBS $\left(\mathrm{OD}_{600} \sim 1\right)$ were coated in wells of a high binding microtiter plate (Nunc MaxiSorp, Thermo Fisher Scientific, Rochester, NY, USA) by incubating overnight at $4{ }^{\circ} \mathrm{C}$. After blocking with 5\% BSA in tris-buffered saline (TBS, $50 \mathrm{mM}$ Tris- $\mathrm{HCl}, \mathrm{pH} 7.5,150 \mathrm{mM}$ $\mathrm{NaCl}$ ), the plates were incubated with the phage library at a final concentration of $1 \times 10^{11}$ $(100 \mu \mathrm{L} /$ well) for $1 \mathrm{~h}$ at room temperature. The unbound phages were removed by washing ten times with TBST (TBS containing 0.05\% Tween-20), and the bound phages were then eluted by adding $100 \mu \mathrm{L}$ of glycine- $\mathrm{HCl}(\mathrm{pH} 2.2,1 \mathrm{mg} / \mathrm{mL} \mathrm{BSA})$ for $10 \mathrm{~min}$. The eluted phages were neutralized with $1 \mathrm{M}$ Tris- $\mathrm{HCl}(15 \mu \mathrm{L}, \mathrm{pH} 9.1)$, amplified, purified, and titrated according to the manufacturer's instructions. Each subsequent selection round used $1 \times 10^{11}$ phage derived from the phage library retrieved in the previous round. After the sixth round of biopanning, DNA was isolated from the selected phage clones and sequenced at Cosmogenetech (Seoul, Korea). The Snapgene viewer software was used to convert the DNA sequences into amino acids (GSL biotech; available at snapgene.com, accessed on 04 October 2021).

\subsection{Preparation of Biotinylated Peptide}

The peptide used in this study was commercially synthesized at Peptron (Daejeon, Korea) via the Fmoc-based solid-phase peptide synthesis protocol. During the synthesis, the peptide was biotinylated by adding a Lys residue at the $\mathrm{COOH}$ terminus with biotin covalently linked to the $\varepsilon$-amine. The biotinylated peptide was prepared to a purity of $>95 \%$ by reversed-phase high-pressure liquid chromatography (HPLC) using a Capcell Pak C18 column (Shiseido, Tokyo, Japan), and the molecular weight of the biotinylated peptide was confirmed by liquid chromatography/mass spectrometry (LCMS-2020, Shimadzu, Kyoto, Japan).

\subsection{Phage Binding ELISA Assay}

The microtiter plates were coated with bacterial cells $\left(1 \times 10^{7}\right.$ colony-forming unit (CFU) / well) overnight at $4{ }^{\circ} \mathrm{C}$ and incubated again with $3 \%$ BSA in TBS for $1 \mathrm{~h}$ at room temperature to block non-specific binding. After washing three times with TBST, one hundred microliters of amplified phages $\left(1 \times 10^{9}\right.$ plaque-forming unit) were added and incubated for $1 \mathrm{~h}$. The wells were washed three times with TBST; subsequently, horseradish peroxidase (HRP)-conjugated anti-M13 monoclonal antibody (1:5000, GE Healthcare, Chicago, IL, USA) was added and incubated for $1 \mathrm{~h}$. The wells were rewashed with TBST, and 2,2'-azino-bis (3-ethylbenzothiazoline-6-sulfonic acid) (ABTS) peroxidase substrate (Sigma-Aldrich, St. Louis, MO, USA) was added to the wells to detect phage binding. The color development at $415 \mathrm{~nm}$ was recorded using a microplate reader (Synergy, BioTeK, Santa Clara, CA, USA).

\subsection{Binding Specificity of KP Peptide}

To analyze the specificity of the peptide identified by phage display, the peptide was subjected to ELISA against different bacteria as described in Section 2.4. The bacterial cells were resuspended in PBS and incubated in ELISA plates overnight at $4{ }^{\circ} \mathrm{C}$ to achieve coating. Subsequently, ELISA was performed using the biotinylated KP peptide $(10 \mu \mathrm{M})$ as the recognition element. The bound peptide was detected using the streptavidin-HRP conjugate (1:2000 in blocking buffer, Thermo Fisher Scientific). 


\subsection{Confocal Laser Scanning Microscopy}

Bacterial cells $\left(1 \times 10^{7} \mathrm{CFU}\right)$ in PBS were inoculated on a poly-L-lysine coated chamber slide at room temperature for $1 \mathrm{~h}$, then washed three times with TBS. Biotinylated KP peptide $(10 \mu \mathrm{M})$ was added to the immobilized bacterial cells for $1 \mathrm{~h}$, and then slides were rewashed with TBS. The bounded peptide was visualized by applying $5 \mathrm{mg} / \mathrm{mL}$ streptavidin-AlexaFluor 488 (Invitrogen, Carlsbad, CA, USA) and observation with an FV1000 confocal laser scanning microscope (Olympus, Tokyo, Japan).

\subsection{Binding of KP Peptide to Lipopolysaccharide}

Lipopolysaccharide (LPS) from K. pneumoniae ATCC 15380, P. aeruginosa ATCC 27316, S. typhimurium ATCC 7823, and lipid A from Salmonella enterica serotype minnesota Re 595 were purchased from Sigma-Aldrich. LPS from E. coli ATCC 12014 was purchased from InvivoGen (San Diego, CA, USA). LPS was also extracted from K. pneumoniae KCTC 2208, E. coli KCTC 2223, P. aeruginosa ATCC 27853, and S. typhimurium KCTC 2370 with the Lipopolysaccharide extraction kit (iNtRON Biotechnology, Seongnam, Korea) according to the manufacturer's instructions. Two milliliters of bacterial cultures with $\mathrm{OD}_{600} \sim$ were pelleted by centrifugation. After applying lysis and purification buffers, the LPS pellet was dissolved by boiling for $3 \mathrm{~min}$. The concentration of extracted LPS was determined by comparing it to a standard curve of commercially available LPS using purpald assay [35].

To examine the binding of KP peptide to LPS, each microtiter plate well was coated with $100 \mu \mathrm{L}$ of LPS ( $2 \mu \mathrm{g} /$ well) in $50 \mathrm{mM} \mathrm{NaHCO} 3, \mathrm{pH} 8.6$ overnight at $4{ }^{\circ} \mathrm{C}$. Biotinylated KP peptide $(10 \mu \mathrm{M})$ or biotinylated polymyxin B (1:50, HycultBiotech, Uden, The Netherlands) was added to the plates. After incubation and washing, the streptavidinHRP conjugate was added to the plate for detection. The other steps were performed as described above (see detailed protocol in Section 2.4).

\subsection{K. pneumoniae O Antigen Typing}

O typing was performed by using a two-step PCR method described by Fang et al. with minor modifications [36]. Genomic DNA was extracted from $2 \mathrm{~mL}$ bacterial solution with a G-spin ${ }^{\mathrm{TM}}$ Genomic DNA Extraction Kit (for bacteria) (iNtRON Biotechnology). Using $10 \mathrm{ng}$ of genomic DNA as the template, PCR was performed with GoTaq ${ }^{\circledR}$ G2 Hot Start Green Master Mix (Promega, Madison, WI, USA) and $0.5 \mu \mathrm{M}$ primers. O1, O2a, O2ac $\mathrm{O} 3, \mathrm{O} 5, \mathrm{O} 8$, and $\mathrm{O} 9$ were determined using two primer pairs for each allele at the wb gene cluster. A genotype is assigned only to the strains that tested positive for both primer pairs. The strains bearing the $\mathrm{O} 1 / \mathrm{O} 2$ allele were examined again with the second set of PCR primers (O1- and O2ac-specific primers). The following cycling conditions were used: $95{ }^{\circ} \mathrm{C}$ for $2 \mathrm{~min}$, then 30 cycles of $95{ }^{\circ} \mathrm{C}$ for $1 \mathrm{~min}, 56^{\circ} \mathrm{C}$ for $1 \mathrm{~min}$, and $72{ }^{\circ} \mathrm{C}$ for $2 \mathrm{~min}$, followed by a 5 min extension at $72{ }^{\circ} \mathrm{C}$. PCR product size was determined on a $1.5 \%$ agarose gel. The primer sequences and PCR product size are shown in Table 1. 
Table 1. Primers used for K. pneumoniae LPS O genotyping by PCR.

\begin{tabular}{|c|c|c|c|}
\hline $\begin{array}{c}\text { O Type } \\
\text { Detected }\end{array}$ & Primer & Sequence $\left(5^{\prime}-3^{\prime}\right)$ & $\begin{array}{l}\text { PCR Product Size } \\
(\mathrm{bp})\end{array}$ \\
\hline \multirow[t]{4}{*}{$\mathrm{O} 1 / \mathrm{O} 2$} & wb O1/O2-A-F & CGCTATAAGAGCAGCATGCTAG & 1251 \\
\hline & wb O1/O2-A-R & CGATATCACCTACTGCCAGA & \\
\hline & wb O1/O2-B-F & TTGTTGAGCCTGACAGGATC & 1589 \\
\hline & wb O1/O2-B-R & GCCATTGCTTGCTTGTACAG & \\
\hline \multirow[t]{2}{*}{ O1 } & wbb O1-F & GATTTCACTTTCCGGGCAAC & 1075 \\
\hline & wbb O1-R & GGCTTGCTGAATCACAAGAC & \\
\hline \multirow[t]{2}{*}{$\mathrm{O} 2 \mathrm{ac}$} & wbb O2ac-F & AAACATCGCTGACTCGAGTC & 1046 \\
\hline & wbb O2ac-R & CGACTATGATCGTACCAACG & \\
\hline \multirow[t]{4}{*}{$\mathrm{O} 3$} & wb O3-A-F & CTATCGCTACCGTGGCTTTA & 767 \\
\hline & wb O3-A-R & TCTCGTCCACAATATCAGCG & \\
\hline & wb O3-B-F & GCCTACAGTATCTACCTCTG & 903 \\
\hline & wb O3-B-R & CGGTAAAGTCAGGATGGAAG & \\
\hline \multirow[t]{4}{*}{ O5 } & wb O5-A-F & GCTACCAAACCAGTATGCTG & 1821 \\
\hline & wb O5-A-R & AGGTGCGTACTGGAAGTATG & \\
\hline & wb O5-B-F & GGTGATGAAAGCCAGAATGC & 1423 \\
\hline & wb O5-B-R & CAGTGCCTGAAACAGTTTGC & \\
\hline \multirow[t]{4}{*}{ O8 } & wb O8-A-F & CGTGGCAATGGTTTGCTAGT & 1230 \\
\hline & wb O8-A-R & TCAATCCACACAACTCGGTC & \\
\hline & wb O8-B-F & GCTAGTTCGGCAACTAACTCAC & 841 \\
\hline & wb O8-B-R & AGTTCCAGCATCGAAGCAACTC & \\
\hline \multirow[t]{4}{*}{ O9 } & wb O9-A-F & CGCGCTCAGTTATTCCATTG & 973 \\
\hline & wb O9-A-R & CTGGCTGATGACAGAGAATC & \\
\hline & wb O9-B-F & GCATTCCTGTTCGTGTATGG & 949 \\
\hline & wb O9-B-R & ATGTCACCGACAGCAAGTAC & \\
\hline
\end{tabular}

2.9. Comparison of Specificity and Sensitivity of KP Peptide with Commercially Available Anti-Klebsiella spp. Antibodies

Ten-fold serial dilutions of log-phase bacterial cultures were added to wells of a microtiter plate and incubated overnight at $4{ }^{\circ} \mathrm{C}$. Biotinylated KP peptide $(10 \mu \mathrm{M})$ and two commercially available biotinylated anti-Klebsiella spp. polyclonal antibodies (1:5000, GTX36396 (Genetex, Irvine, CA, USA), ab69468 (Abcam, Cambridge, UK)) were added to the plate. After incubation and washing, the streptavidin-HRP conjugate was added to the plate for detection. The other steps were performed as described above (see detailed protocol in Section 2.4).

\section{Results and Discussion}

\subsection{Biopanning of a Phage Display Library against K. pneumoniae}

The one-bead, one-compound (OBOC) combinatorial peptide library and the phagedisplayed peptide library are the two most popular approaches that have been successfully used for the discovery of novel peptide ligands $[37,38]$. The OBOC strategy allows for the use of building blocks other than natural amino acids such as $\mathrm{D}^{\text {-amino acids, which can }}$ confer protease resistance $[39,40]$, but OBOC screening is technically difficult and typically examines only $\sim 10^{6}$ compounds [41,42]. The main advantage of the phage-displayed peptide library is that it can generate a library with higher sequence diversity $\left(10^{9}\right.$ for phage-displayed library vs. $10^{6}$ for OBOC library), which is critical for the selection and screening of high-affinity peptides. Because of its unparalleled diversity and commercial availability, we used a phage-displayed random peptide library to isolate clones displaying peptides that can bind specifically to the whole K. pneumoniae cell surface. After eliminating the phages that interacted with BSA, K. pneumoniae was probed by the remaining phages in the peptide library. After washing to remove the unbound phages, K. pneumoniae-binding phages were eluted, propagated, and purified for input in the next round of biopanning. 
After six rounds of biopanning, 24 phage clones were randomly selected from the eluted phage population and amplified. Genomic DNA was extracted from each amplified phage and sequenced to determine the peptide sequence displayed in the major coat protein. All 24 clones were found to encode the same peptide sequence (TSATKFMMNLSP).

\subsection{Specificity of Phage Binding to K. pneumoniae}

Specificity is the ability of a recognition element to interact preferentially with the target over other potential ones. To determine the recognition specificity, we examined the ability of the selected phage clone to interact preferentially with K. pneumoniae compared to other possible targets, including Gram-negative bacteria (E. coli, P. aeruginosa, P. putida, S. typhimurium, and S. enteritidis) and Gram-positive bacteria (S. aureus, S. epidermidis, E. faecalis, B. subtilis, and L. lactis). The results shown in Figure 1 suggest that the selected phage clone bound specifically to K. pneumoniae and did not cross-react with other species. Hence, the peptide sequence displayed in the major coat protein of the selected phage clone (TSATKFMMNLSP, named KP peptide) was synthesized and further tested for its suitability as a recognition element for K. pneumoniae detection.

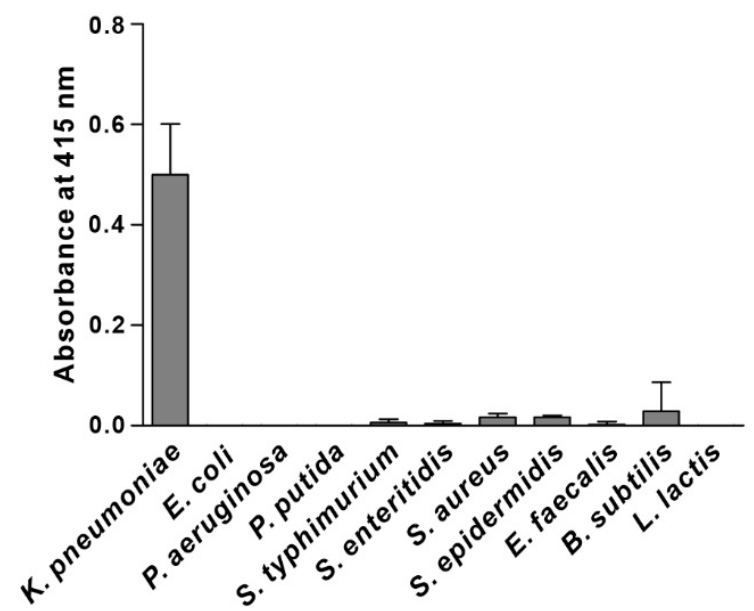

Figure 1. Specificity and selectivity of phage clone binding to K. pneumoniae. The binding of the selected phage clone to different bacterial cells was determined by phage-binding ELISA. Microtiter plates were coated with bacterial cells, incubated with the selected phage clone, and then incubated with HRP-conjugated anti-M13 antibody. The substrate ABTS was used to detect the positive binding of the phage clone to bacteria. The data are presented as the mean $\pm \mathrm{SD}$ of three independent experiments performed in triplicate.

\subsection{Specificity of KP Peptide Binding to K. pneumoniae}

We synthesized the KP peptide with a C-terminal Lys as a biotin tag and investigated the ability of this peptide to interact preferentially with $K$. pneumoniae relative to a panel of selected Gram-negative bacteria and Gram-positive bacteria. As illustrated in Figure 2, KP peptide showed significant binding to K. pneumoniae and little or no binding to the other bacterial strains as observed with the phage-binding ELISA. We then assessed the binding capacity of KP peptide against seven clinically isolated K. pneumoniae strains, including antibiotic-resistant strains (Figure 3). ELISA assay confirmed that KP peptide is a specific and selective recognition element for different $K$. pneumoniae strains, including the antibiotic-resistant strains. As the KP peptide showed specific binding to K. pneumoniae in ELISA, we further investigated its ability to bind to the target bacterium using confocal laser scanning microscopy. Figure 4 demonstrates that the peptide was explicitly bound to the outer surface of K. pneumoniae, supporting the ELISA results. 


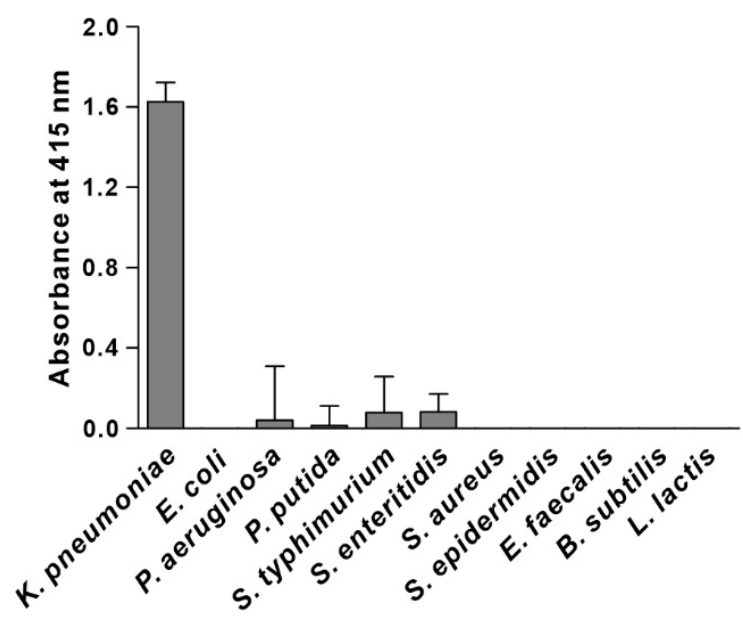

Figure 2. Specificity and selectivity of KP peptide binding to K. pneumoniae. The binding activity of KP peptide to different bacterial cells was determined by peptide-binding ELISA. Microtiter plates were coated with bacterial cells and incubated with the biotinylated KP peptide. The bound peptide was detected by HRP-conjugated streptavidin and the substrate ABTS. The data are presented as the mean \pm SD of three independent experiments performed in triplicate.

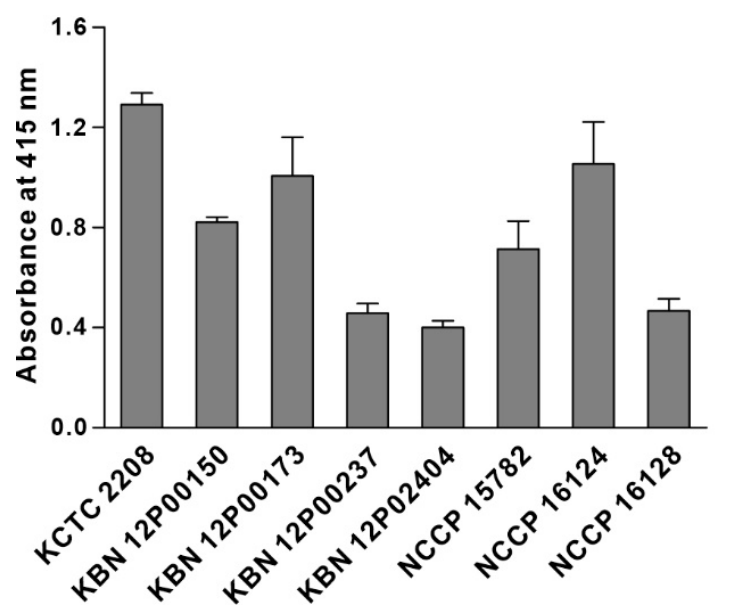

Figure 3. Capacity of KP peptide to detect clinical K. pneumoniae isolates. Microtiter plates were coated with K. pneumoniae KCTC 2208 and seven clinical isolates and incubated with the biotinylated KP peptide. The bound peptide was detected by HRP-conjugated streptavidin and the substrate ABTS. The data are presented as the mean \pm SD of three independent experiments performed in triplicate. 


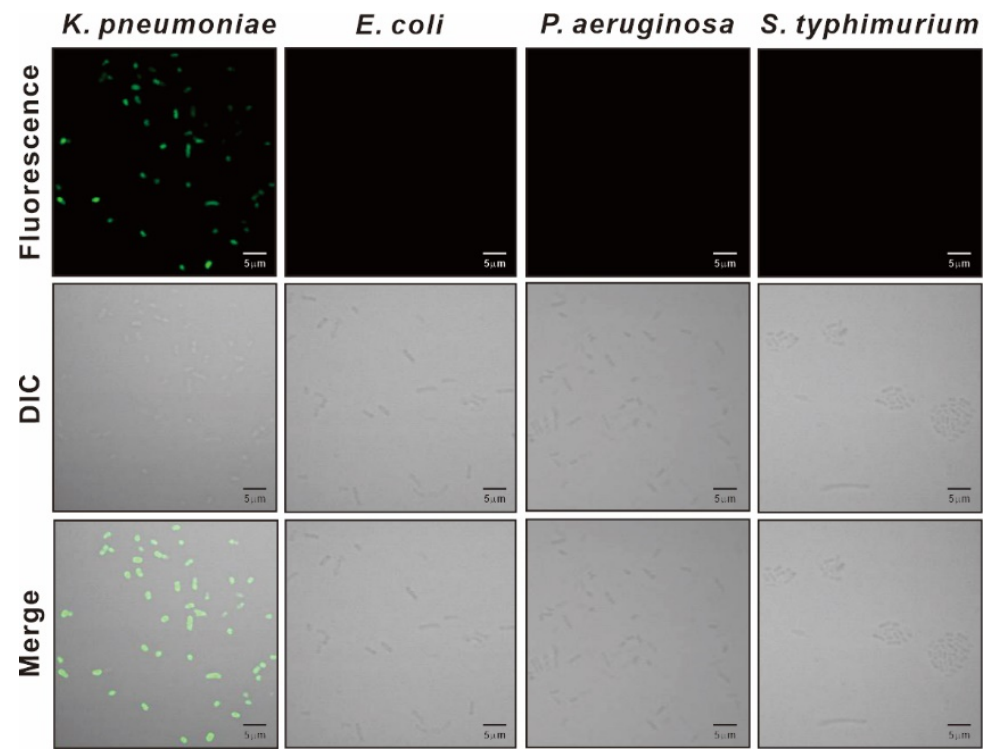

Figure 4. Confocal laser scanning microscopy of bacteria treated with KP peptide. Bacterial cells were incubated with the biotinylated KP peptide and visualized with Alexa 488-labeled streptavidin.

\subsection{Characterization of the Binding Specificity of KP Peptide}

To identify potential binding targets for the KP peptide on the surface of K. pneumoniae, we first checked whether KP peptide binds to outer membrane proteins on K. pneumoniae. Total outer membrane proteins (OMPs) of K. pneumoniae were isolated, and far-western blotting analysis and pull-down assay were performed by using biotinylated KP peptide as a probe, as previously described [34]. For far-western blotting, total OMPs were separated by SDS-PAGE, blotted to a PVDF membrane and probed with biotinylated KP peptide. For pull-down assay, OMPs and biotinylated KP peptide were mixed and pulled down through conjugation with streptavidin-coupled magnetic beads. The captured proteins were separated and visualized by Coomassie blue staining. We could not detect any band in both assays, suggesting that KP peptide did not bind to outer membrane proteins on K. pneumoniae (data not shown). Next, we investigated the ability of the KP peptide to interact with LPS, which is the major component of the outer membrane of Gram-negative bacteria. LPS was extracted from various Gram-negative bacteria, and its association with KP peptide was examined by ELISA. As shown in Figure 5a, KP peptide strongly bound to LPS from K. pneumoniae compared with LPS from other bacteria. To verify the finding that KP peptide bound to K. pneumoniae LPS, KP peptide binding to the commercially available LPS from different bacterial strains was investigated. We also included lipid A in the assay to observe whether KP peptide can bind to the highly conserved lipid A portion of LPS. Polymyxin B was used as a positive control due to its strong binding capacity for lipid A. As shown in Figure 5b, polymyxin B displayed a high affinity towards all the tested LPS, with the maximum affinity for lipid A. In contrast to polymyxin B, KP peptide bound to a great extent to LPS derived from K. pneumoniae, whereas little binding was observed for lipid A and LPS derived from other bacteria. Overall, these data indicated that KP peptide binds specifically to LPS on K. pneumoniae, and this specificity might not be the result of the binding to lipid A. 
(a)

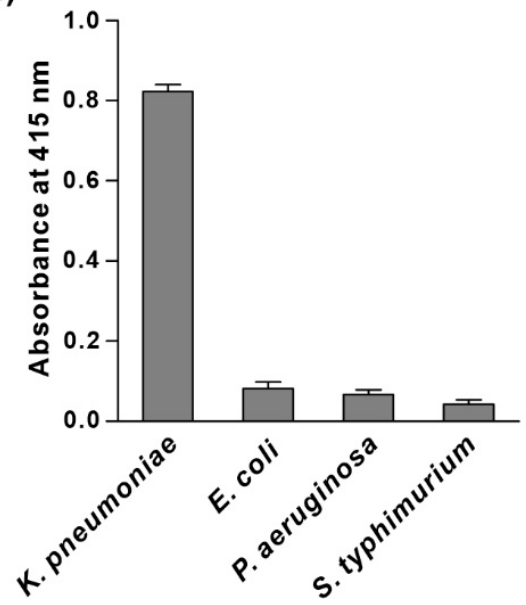

(b)

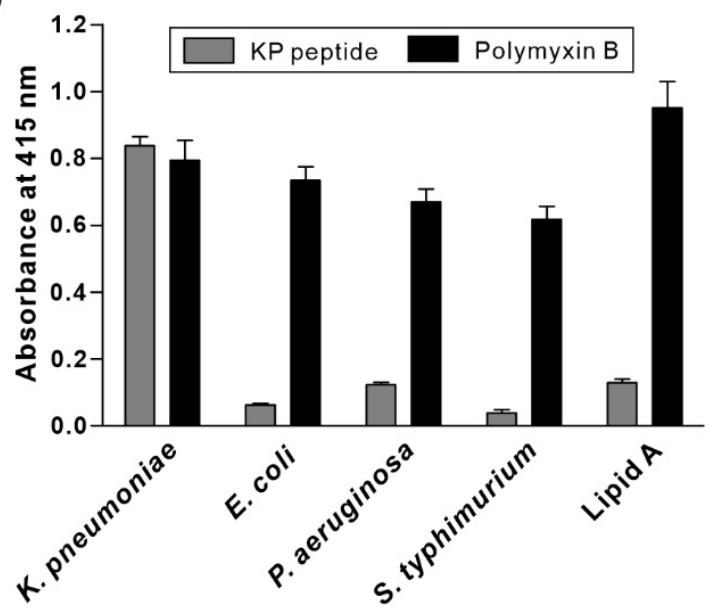

Figure 5. Validation of binding activity of KP peptide to LPS. The binding of KP peptide to LPS from K. pneumoniae and their cross binding to LPS from the other Gram-negative bacteria were determined by peptide-binding ELISA. Extracted LPS (a), commercially available LPS, and lipid A (b) were coated onto microtiter plates. Peptides (biotinylated KP peptide and polymyxin B) bound to the coated LPS were detected by HRP-conjugated streptavidin and the substrate ABTS. The data are presented as the mean \pm SD of three independent experiments performed in triplicate.

As in other Enterobacteriaceae, three domains are recognized in the K. pneumoniae LPS: the highly conserved lipid $\mathrm{A}$, the highly variable $\mathrm{O}$ antigen polysaccharide, and the core oligosaccharide connecting lipid A and O antigen. To determine to which part of the LPS the KP peptide binds specifically, we performed $\mathrm{O}$ typing on eight $K$. pneumoniae strains, which were used in the ELISA binding assay in Figure 3. The $\mathrm{O}$ antigen differs significantly between K. pneumoniae strains based on the sugar residues and their linkage patterns within the repeating subunits and is classified into 11 serotypes: O1, O2a, O2ac, O2afg, O2aeh (O9), O3, O4, O5, O7, O8, and O12 [43]. When the galactose-based polysaccharides (O1, $\mathrm{O} 2$, O8, and $\mathrm{O} 9$ serotype) and mannose-based polysaccharides (O3 and O5 serotype) were determined, the results showed that five K. pneumoniae strains (KCTC 2208, KBN 12P00150, KBN 12P00237, KBN 12P02404, and NCCP 16128) belonged to the O1 serotype, while the remaining three strains belonged to other $\mathrm{O}$ serotypes (i.e., they did not belong to $\mathrm{O} 1, \mathrm{O} 2$, $\mathrm{O} 3, \mathrm{O} 5, \mathrm{O} 8$, and O9) (Figure 6). These results suggested that $\mathrm{O}$ antigen is not the main target of KP peptide because KP peptide could bind to multiple K. pneumoniae strains with different $\mathrm{O}$ antigens, as shown in Figure 3. In contrast to $\mathrm{O}$ antigens, two types of core oligosaccharides were described in K. pneumoniae; both share the same inner core and outer core proximal disaccharide with differences in the glucosamine substituents [44,45]. The inner core of K. pneumoniae differs from those of E. coli and Salmonella, though the inner core is highly conserved within the Enterobacteriaceae $[45,46]$. We thus hypothesized that the specificity of the KP peptide is due to its interaction with the core oligosaccharide region of K. pneumoniae LPS. However, additional research is required to validate our hypothesis. 
(a)

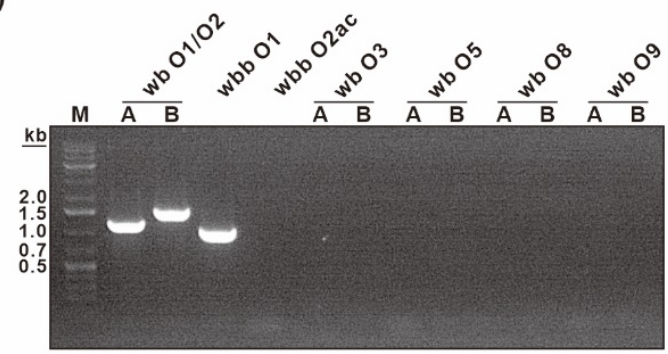

(c)

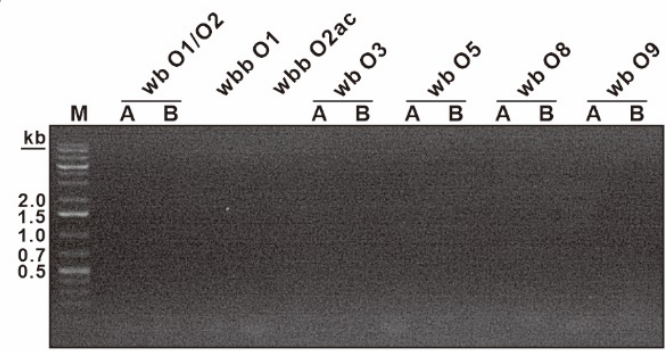

(e)

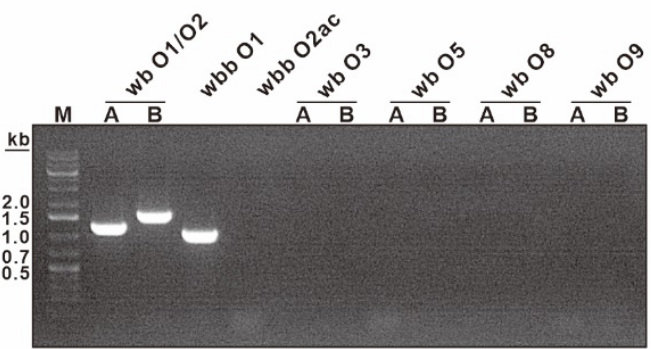

(g)

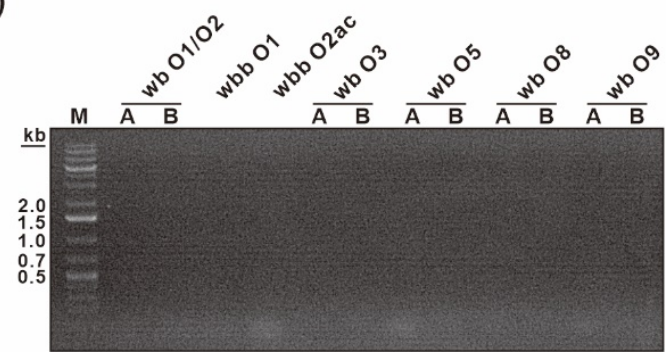

(b)

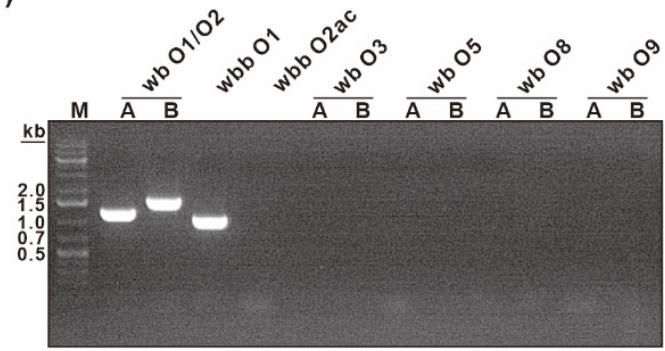

(d)

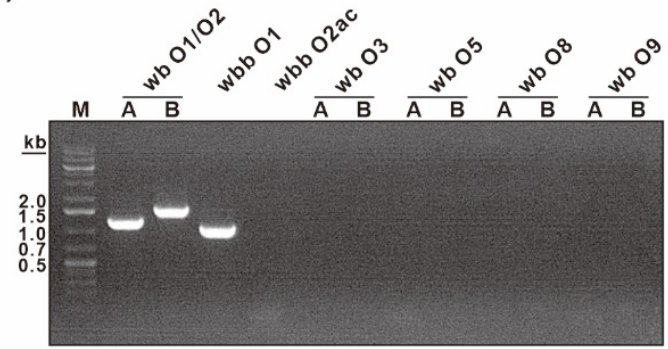

(f)

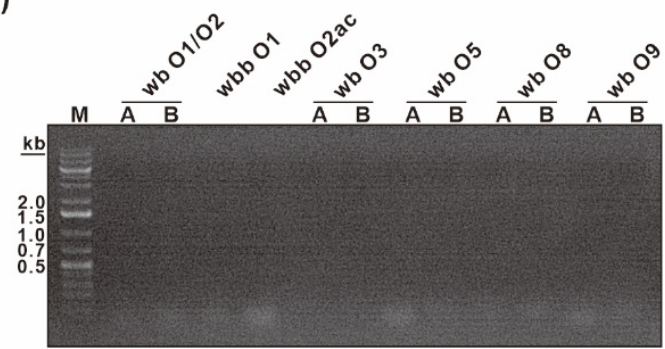

(h)

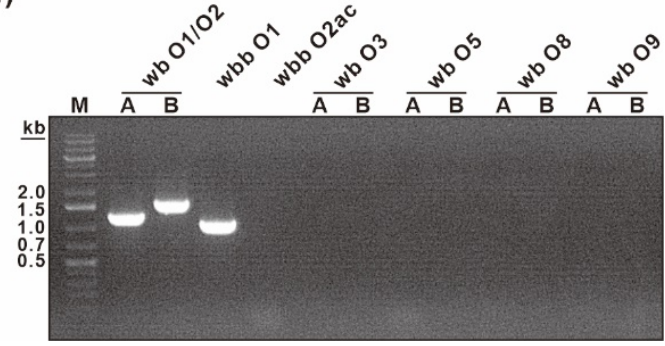

Figure 6. Genotyping of $\mathrm{O}$ antigen in a panel of clinical K. pneumoniae isolates by PCR. Agarose gel images showing the PCR amplification of the primers using the genomic DNA of K. pneumoniae as the template were presented. The primer pair name was indicated on top of each lane. The band sizes of the DNA ladder are shown on the left. (a) K. pneumoniae KCTC 2208, (b) K. pneumoniae KBN 12P00150, (c) K. pneumoniae KBN 12P00173, (d) K. pneumoniae KBN 12P00237, (e) K. pneumoniae KBN 12P02404, (f) K. pneumoniae NCCP 15782 (g) K. pneumoniae NCCP 16124, (h) K. pneumoniae NCCP 16128.

\subsection{Comparison of Specificity and Sensitivity of KP Peptide with Commercially Available} Anti-Klebsiella spp. Antibodies

To evaluate the suitability of KP peptide as a recognition element for the detection of $K$. pneumoniae, specificity and sensitivity were compared with that of commercially available anti-Klebsiella spp. antibodies. Biotinylated KP peptide or antibodies were incubated with pre-immobilized Gram-negative bacterial cells (from $10^{2}$ to $10^{8} \mathrm{CFU} / \mathrm{mL}$ ), and the binding interaction was measured using ELISA. As shown in Figure 7, anti-Klebsiella spp. antibodies showed specific binding for K. pneumoniae at bacterial concentrations ranging from $10^{5}$ to $10^{6} \mathrm{CFU} / \mathrm{mL}$. However, their specificity for K. pneumoniae was decreased as the number of bacterial cells was increased from $10^{7}$ to $10^{8} \mathrm{CFU} / \mathrm{mL}$. In contrast, KP peptide showed good specificity for K. pneumoniae at all the tested bacterial concentrations compared to 
that for other Gram-negative bacteria. Moreover, the detection limit of KP peptide was $10^{4} \mathrm{CFU} / \mathrm{mL}$, which was ten times more sensitive than anti-Klebsiella spp. antibodies. These data indicated that KP peptide is more specific and sensitive than anti-Klebsiella spp. antibodies as a recognition element for detecting K. pneumoniae.

(a)

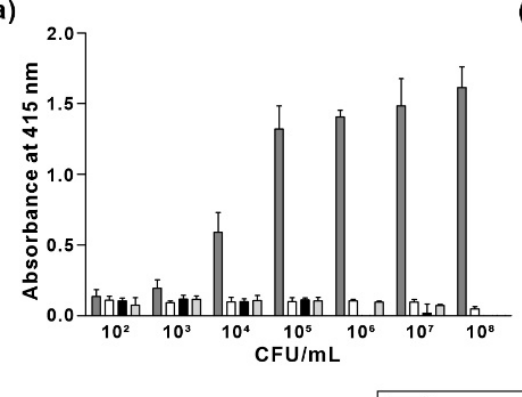

(b)

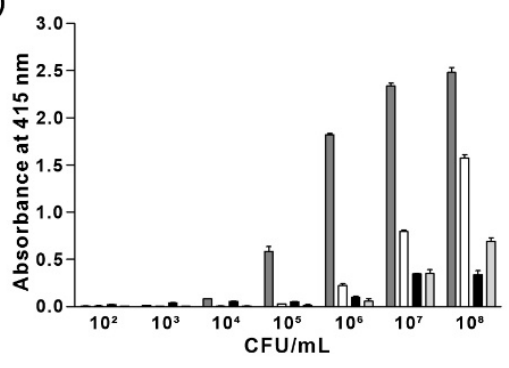

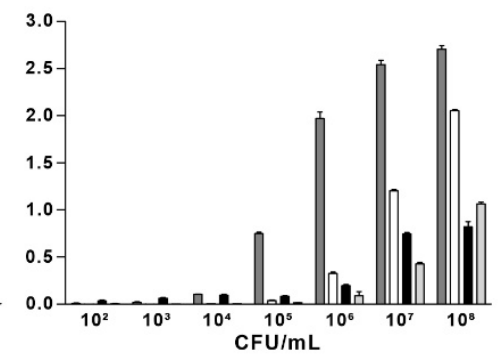

K. pneumoniae $\square$ E.coli

P. aeruginosa $\square$ S. typhimurium

Figure 7. Comparison of specificity and sensitivity of KP peptide with commercially available antiKlebsiella spp. antibodies. Microtiter plates were coated with different concentrations of bacterial cells $\left(10^{2}-10^{8} \mathrm{CFU} / \mathrm{mL}\right)$ and incubated with biotinylated KP peptide (a) or anti-Klebsiella spp. antibodies [(b) left: ab69468; right: GTX36396] prior to incubation with streptavidin-HRP. The substrate ABTS was used to detect the positive binding of the peptide or antibodies to bacteria. The data are presented as the mean $\pm \mathrm{SD}$ of three independent experiments performed in triplicate.

Because ELISA is not suitable for pathogen detection at the point-of-care, proper detection methods should be developed in the future to use this peptide as a recognition element for a biosensor analytical device for K. pneumoniae detection at the point-of-care. As a common strategy to improve the sensitivity and accuracy of detection methods, the preconcentration to the low-abundant analytes can be used. Immunomagnetic nanoparticles, which can enrich the cells rapidly without bacterial cultivation and centrifugation, might be used for the detection method $[47,48]$. Future work will focus on the development of a KP peptide-based biosensor for K. pneumoniae detection.

\section{Conclusions}

The discovery of novel peptide sequences that specifically bind to the target bacteria can be regarded as a first step toward the development of a bacterial detection system. In this study, we identified a unique short peptide (KP peptide, TSATKFMMNLSP) specific to K. pneumoniae cells from the biopanning of the M13 phage display peptide library and measured the binding interactions of the peptide-displayed phage clone and the synthetic peptide using ELISA. KP peptide was specific to K. pneumoniae and had low cross-reactivity with other Gram-negative bacteria. The selectivity of the KP peptide against K. pneumoniae resulted from the specific interaction between the KP peptide and K. pneumoniae LPS. Furthermore, KP peptide possessed higher specificity and sensitivity toward K. pneumoniae than commercially available anti-Klebsiella spp. antibodies. This peptide that selectively binds to and detects K. pneumoniae might be a cost-effective alternative to antibodies and a useful diagnostic tool for the detection of K. pneumoniae.

Author Contributions: Conceptualization, J.H.C.; Funding acquisition, J.H.C. and H.K.; Investigation, H.K., J.H.J. and I.Y.J.; Writing-original draft, H.K. and J.H.C.; Writing-review and editing, J.H.J. and J.H.C. All authors have read and agreed to the published version of the manuscript.

Funding: This work was supported by Basic Science Research Program through the National Research Foundation of Korea (NRF) funded by the Ministry of Science and ICT (2020R1I1A3051795 and 2020R1I1A1A01051710).

Institutional Review Board Statement: Not applicable.

Informed Consent Statement: Not applicable. 
Data Availability Statement: Not applicable.

Conflicts of Interest: The authors declare no conflict of interest.

\section{References}

1. Haque, M.; Sartelli, M.; McKimm, J.; Abu Bakar, M. Healthcare-associated infections-An overview. Infect. Drug Resist. 2018, 11, 2321-2333. [CrossRef] [PubMed]

2. Paczosa, M.K.; Mecsas, J. Klebsiella pneumoniae: Going on the Offense with a Strong Defense. Microbiol. Mol. Biol. Rev. 2016, 80, 629-661. [CrossRef] [PubMed]

3. Dao, T.T.; Liebenthal, D.; Tran, T.K.; Ngoc Thi Vu, B.; Ngoc Thi Nguyen, D.; Thi Tran, H.K.; Thi Nguyen, C.K.; Thi Vu, H.L.; Fox, A.; Horby, P.; et al. Klebsiella pneumoniae oropharyngeal carriage in rural and urban Vietnam and the effect of alcohol consumption. PLoS ONE 2014, 9, e91999. [CrossRef]

4. $\quad$ Fung, C.P.; Lin, Y.T.; Lin, J.C.; Chen, T.L.; Yeh, K.M.; Chang, F.Y.; Chuang, H.C.; Wu, H.S.; Tseng, C.P.; Siu, L.K. Klebsiella pneumoniae in gastrointestinal tract and pyogenic liver abscess. Emerg. Infect. Dis. 2012, 18, 1322-1325. [CrossRef] [PubMed]

5. Gorrie, C.L.; Mirceta, M.; Wick, R.R.; Edwards, D.J.; Thomson, N.R.; Strugnell, R.A.; Pratt, N.F.; Garlick, J.S.; Watson, K.M.; Pilcher, D.V.; et al. Gastrointestinal Carriage Is a Major Reservoir of Klebsiella pneumoniae Infection in Intensive Care Patients. Clin. Infect. Dis. 2017, 65, 208-215. [CrossRef] [PubMed]

6. Snitkin, E.S.; Zelazny, A.M.; Thomas, P.J.; Stock, F.; Group, N.C.S.P.; Henderson, D.K.; Palmore, T.N.; Segre, J.A. Tracking a hospital outbreak of carbapenem-resistant Klebsiella pneumoniae with whole-genome sequencing. Sci. Transl. Med. 2012, 4, 148 ra116. [CrossRef]

7. Young, T.M.; Bray, A.S.; Nagpal, R.K.; Caudell, D.L.; Yadav, H.; Zafar, M.A. Animal Model to Study Klebsiella pneumoniae Gastrointestinal Colonization and Host-to-Host Transmission. Infect. Immun. 2020, 88, e00071-20. [CrossRef]

8. Pena, C.; Pujol, M.; Ardanuy, C.; Ricart, A.; Pallares, R.; Linares, J.; Ariza, J.; Gudiol, F. Epidemiology and successful control of a large outbreak due to Klebsiella pneumoniae producing extended-spectrum beta-lactamases. Antimicrob. Agents Chemother. 1998, 42, 53-58. [CrossRef]

9. Viau, R.A.; Hujer, A.M.; Marshall, S.H.; Perez, F.; Hujer, K.M.; Briceno, D.F.; Dul, M.; Jacobs, M.R.; Grossberg, R.; Toltzis, P.; et al. "Silent" dissemination of Klebsiella pneumoniae isolates bearing K. pneumoniae carbapenemase in a long-term care facility for children and young adults in Northeast Ohio. Clin. Infect. Dis. 2012, 54, 1314-1321. [CrossRef]

10. Casewell, M.; Phillips, I. Hands as route of transmission for Klebsiella species. Br. Med. J. 1977, 2, 1315-1317. [CrossRef]

11. Sakkas, H.; Bozidis, P.; Ilia, A.; Mpekoulis, G.; Papadopoulou, C. Antimicrobial Resistance in Bacterial Pathogens and Detection of Carbapenemases in Klebsiella pneumoniae Isolates from Hospital Wastewater. Antibiotics 2019, 8, 85. [CrossRef]

12. Bowers, J.R.; Kitchel, B.; Driebe, E.M.; MacCannell, D.R.; Roe, C.; Lemmer, D.; de Man, T.; Rasheed, J.K.; Engelthaler, D.M.; Keim, P.; et al. Genomic Analysis of the Emergence and Rapid Global Dissemination of the Clonal Group 258 Klebsiella pneumoniae Pandemic. PLoS ONE 2015, 10, e0133727. [CrossRef] [PubMed]

13. Ko, J.H.; Baek, J.Y.; Peck, K.R.; Cho, S.Y.; Ha, Y.E.; Kim, S.H.; Huh, H.J.; Lee, N.Y.; Kang, C.I.; Chung, D.R.; et al. Discrepant susceptibility to gentamicin despite amikacin resistance in Klebsiella pneumoniae by VITEK 2 represents false susceptibility associated with the armA 16S rRNA methylase gene. J. Med. Microbiol. 2017, 66, 1448-1450. [CrossRef] [PubMed]

14. Liu, Y.; Liu, C.; Zheng, W.; Zhang, X.; Yu, J.; Gao, Q.; Hou, Y.; Huang, X. PCR detection of Klebsiella pneumoniae in infant formula based on 16S-23S internal transcribed spacer. Int. J. Food Microbiol. 2008, 125, 230-235. [CrossRef] [PubMed]

15. Jeong, E.S.; Lee, K.S.; Heo, S.H.; Seo, J.H.; Choi, Y.K. Rapid identification of Klebsiella pneumoniae, Corynebacterium kutscheri, and Streptococcus pneumoniae using triplex polymerase chain reaction in rodents. Exp. Anim. 2013, 62, 35-40. [CrossRef]

16. Shannon, K.E.; Lee, D.Y.; Trevors, J.T.; Beaudette, L.A. Application of real-time quantitative PCR for the detection of selected bacterial pathogens during municipal wastewater treatment. Sci. Total Environ. 2007, 382, 121-129. [CrossRef]

17. Yoon, E.J.; Lee, E.H.; Hwang, D.H.; Lee, H.; Baek, J.H.; Jeong, S.H. Direct detection of intact Klebsiella pneumoniae carbapenemases produced by Enterobacterales using MALDI-TOF MS. J. Antimicrob. Chemother. 2020, 75, 1174-1181. [CrossRef]

18. Huang, Y.; Li, J.; Wang, Q.; Tang, K.; Li, C. Rapid detection of KPC-producing Klebsiella pneumoniae in China based on MALDI-TOF MS. J. Microbiol. Methods 2022, 192, 106385. [CrossRef]

19. Zelcbuch, L.; Yitzhaki, E.; Nissan, O.; Gidron, E.; Buchshtab, N.; Kario, E.; Kredo-Russo, S.; Zak, N.B.; Bassan, M. Luminescent Phage-Based Detection of Klebsiella pneumoniae: From Engineering to Diagnostics. Pharmaceuticals 2021, 14, 347. [CrossRef]

20. Ahmadi, S.; Kamaladini, H.; Haddadi, F.; Sharifmoghadam, M.R. Thiol-Capped Gold Nanoparticle Biosensors for Rapid and Sensitive Visual Colorimetric Detection of Klebsiella pneumoniae. J. Fluoresc. 2018, 28, 987-998. [CrossRef]

21. Tominaga, T. Rapid detection of Klebsiella pneumoniae, Klebsiella oxytoca, Raoultella ornithinolytica and other related bacteria in food by lateral-flow test strip immunoassays. J. Microbiol. Methods 2018, 147, 43-49. [CrossRef] [PubMed]

22. Hussain, W.; Ullah, M.W.; Farooq, U.; Aziz, A.; Wang, S. Bacteriophage-based advanced bacterial detection: Concept, mechanisms, and applications. Biosens. Bioelectron. 2021, 177, 112973. [CrossRef] [PubMed]

23. Yoo, S.M.; Lee, S.Y. Optical Biosensors for the Detection of Pathogenic Microorganisms. Trends Biotechnol. 2016, 34, 7-25. [CrossRef] [PubMed]

24. Ahmed, A.; Rushworth, J.V.; Hirst, N.A.; Millner, P.A. Biosensors for whole-cell bacterial detection. Clin. Microbiol. Rev. 2014, 27, 631-646. [CrossRef] [PubMed] 
25. Ladner, R.C.; Sato, A.K.; Gorzelany, J.; de Souza, M. Phage display-derived peptides as therapeutic alternatives to antibodies. Drug Discov. Today 2004, 9, 525-529. [CrossRef]

26. Park, J.P.; Cropek, D.M.; Banta, S. High affinity peptides for the recognition of the heart disease biomarker troponin I identified using phage display. Biotechnol. Bioeng. 2010, 105, 678-686. [CrossRef]

27. Lim, J.M.; Heo, N.S.; Oh, S.Y.; Ryu, M.Y.; Seo, J.H.; Park, T.J.; Huh, Y.S.; Park, J.P. Selection of affinity peptides for interference-free detection of cholera toxin. Biosens. Bioelectron. 2018, 99, 289-295. [CrossRef]

28. De Plano, L.M.; Carnazza, S.; Messina, G.M.L.; Rizzo, M.G.; Marletta, G.; Guglielmino, S.P.P. Specific and selective probes for Staphylococcus aureus from phage-displayed random peptide libraries. Colloids Surf. B Biointerfaces 2017, 157, 473-480. [CrossRef]

29. Rao, S.S.; Mohan, K.V.; Gao, Y.; Atreya, C.D. Identification and evaluation of a novel peptide binding to the cell surface of Staphylococcus aureus. Microbiol. Res. 2013, 168, 106-112. [CrossRef]

30. Carnazza, S.; Foti, C.; Gioffre, G.; Felici, F.; Guglielmino, S. Specific and selective probes for Pseudomonas aeruginosa from phage-displayed random peptide libraries. Biosens. Bioelectron. 2008, 23, 1137-1144. [CrossRef]

31. Agrawal, S.; Kulabhusan, P.K.; Joshi, M.; Bodas, D.; Paknikar, K.M. A high affinity phage-displayed peptide as a recognition probe for the detection of Salmonella Typhimurium. J. Biotechnol. 2016, 231, 40-45. [CrossRef] [PubMed]

32. Sorokulova, I.B.; Olsen, E.V.; Chen, I.H.; Fiebor, B.; Barbaree, J.M.; Vodyanoy, V.J.; Chin, B.A.; Petrenko, V.A. Landscape phage probes for Salmonella typhimurium. J. Microbiol. Methods 2005, 63, 55-72. [CrossRef]

33. Sainath Rao, S.; Mohan, K.V.; Nguyen, N.; Abraham, B.; Abdouleva, G.; Zhang, P.; Atreya, C.D. Peptides panned from a phage-displayed random peptide library are useful for the detection of Bacillus anthracis surrogates B. cereus 4342 and B. anthracis Sterne. Biochem. Biophys. Res. Commun. 2010, 395, 93-98. [CrossRef]

34. Kim, H.; Jang, J.H.; Kim, S.C.; Cho, J.H. Development of a novel hybrid antimicrobial peptide for targeted killing of Pseudomonas aeruginosa. Eur. J. Med. Chem. 2020, 185, 111814. [CrossRef] [PubMed]

35. Lu, X.J.; Ning, Y.J.; Liu, H.; Nie, L.; Chen, J. A Novel Lipopolysaccharide Recognition Mechanism Mediated by Internalization in Teleost Macrophages. Front. Immunol. 2018, 9, 2758. [CrossRef]

36. Fang, C.T.; Shih, Y.J.; Cheong, C.M.; Yi, W.C. Rapid and Accurate Determination of Lipopolysaccharide O-Antigen Types in Klebsiella pneumoniae with a Novel PCR-Based O-Genotyping Method. J. Clin. Microbiol. 2016, 54, 666-675. [CrossRef]

37. Liu, R.; Li, X.; Xiao, W.; Lam, K.S. Tumor-targeting peptides from combinatorial libraries. Adv. Drug Deliv. Rev. 2017, 110-111, 13-37. [CrossRef] [PubMed]

38. Wu, C.H.; Liu, I.J.; Lu, R.M.; Wu, H.C. Advancement and applications of peptide phage display technology in biomedical science J. Biomed. Sci. 2016, 23, 8. [CrossRef]

39. Agnew, H.D.; Coppock, M.B.; Idso, M.N.; Lai, B.T.; Liang, J.; McCarthy-Torrens, A.M.; Warren, C.M.; Heath, J.R. Protein-Catalyzed Capture Agents. Chem. Rev. 2019, 119, 9950-9970. [CrossRef]

40. Chan, K.H.; Lim, J.; Jee, J.E.; Aw, J.H.; Lee, S.S. Peptide-Peptide Co-Assembly: A Design Strategy for Functional Detection of C-peptide, A Biomarker of Diabetic Neuropathy. Int. J. Mol. Sci. 2020, 21, 9671. [CrossRef]

41. Schwaar, T.; Lettow, M.; Remmler, D.; Börner, H.G.; Weller, M.G. Efficient Screening of Combinatorial Peptide Libraries by Spatially Ordered Beads Immobilized on Conventional Glass Slides. High Throughput 2019, 8, 11. [CrossRef] [PubMed]

42. Gates, Z.P.; Vinogradov, A.A.; Quartararo, A.J.; Bandyopadhyay, A.; Choo, Z.N.; Evans, E.D.; Halloran, K.H.; Mijalis, A.J.; Mong, S.K.; Simon, M.D.; et al. Xenoprotein engineering via synthetic libraries. Proc. Natl. Acad. Sci. USA 2018, 115, E5298-E5306. [CrossRef] [PubMed]

43. Arato, V.; Raso, M.M.; Gasperini, G.; Berlanda Scorza, F.; Micoli, F. Prophylaxis and Treatment against Klebsiella pneumoniae: Current Insights on This Emerging Anti-Microbial Resistant Global Threat. Int. J. Mol. Sci. 2021, 22, 4042. [CrossRef] [PubMed]

44. Vinogradov, E.; Perry, M.B. Structural analysis of the core region of the lipopolysaccharides from eight serotypes of Klebsiella pneumoniae. Carbohydr. Res. 2001, 335, 291-296. [CrossRef]

45. Regue, M.; Izquierdo, L.; Fresno, S.; Pique, N.; Corsaro, M.M.; Naldi, T.; De Castro, C.; Waidelich, D.; Merino, S.; Tomas, J.M. A second outer-core region in Klebsiella pneumoniae lipopolysaccharide. J. Bacteriol. 2005, 187, 4198-4206. [CrossRef]

46. Vinogradov, E.; Cedzynski, M.; Ziolkowski, A.; Swierzko, A. The structure of the core region of the lipopolysaccharide from Klebsiella pneumoniae O3. 3-deoxy-alpha-D-manno-octulosonic acid (alpha-Kdo) residue in the outer part of the core, a common structural element of Klebsiella pneumoniae O1, O2, O3, O4, O5, O8, and O12 lipopolysaccharides. Eur. J. Biochem. 2001, 268, 1722-1729.

47. Zhang, L.; Shi, Y.; Chen, C.; Han, Q.; Chen, Q.; Xia, X.; Song, Y.; Zhang, J. Rapid, Visual Detection of Klebsiella pneumoniae Using Magnetic Nanoparticles and an Horseradish Peroxidase-Probe Based Immunosensor. J. Biomed. Nanotechnol. 2019, 15, 1061-1071. [CrossRef]

48. Zhang, L.; Wuzhen, G.C.; Wang, Q.S.; Wang, M.; Lin, J. Optical Biosensors for Rapid Detection of Salmonella typhimurium Based on Porous Gold@Platinum Nanocatalysts and a 3D Fluidic Chip. ACS Sens. 2020, 5, 65-72. [CrossRef] 